\title{
PARTISIPASI PERAWAT DALAM BUDAYA KESELAMATAN PASIEN DI RUANG RAWAT INAP
}

\author{
Hanita Grace Sagala hanitagrace10@gmail.com
}

\begin{abstract}
ABSTRAK
Perawatan rawat inap memiliki peran penting dalam pelayanan perawatan untuk observasi, diagnosis, pengobatan atau upaya perawatan kesehatan lainnya. Keselamatan pasien di rumah sakit melibatkan partisipasi dari semua petugas kesehatan, terutama perawat. Perawat sebagai salah satu tenaga kesehatan yang mempunyai jumlah cukup dominan di rumah sakit yaitu sebesar 50 sampai $60 \%$ dari jumlah tenaga kesehatan yang ada. Pelayanan asuhan keperawatan yang diberikan kepada pasien merupakan pelayanan yang terintegrasi dari pelayanan kesehatan yang lainnya dan memiliki peran yang cukup penting bagi terwujudnya kesehatan dan keselamatan pasien.
\end{abstract}

Kata kunci : Rawat inap, budaya keselamatan, perawat

LATAR BELAKANG

Rumah sakit adalah sarana pelayanan kesehatan yang dibutuhkan ketika seseorang sakit dan membutuhkan bantuan dengan tujuan untuk menyelamatkan kondisi pasien. Dengan berlalunya waktu dan perkembangan ilmu pengetahuan dan teknologi rumah sakit tidak hanya menjadi tempat untuk menyelamatkan pasien. Berbagai layanan dapat diakses oleh pasien yang membutuhkan bantuan. Pasien yang memerlukan bantuan menyeluruh dan intensif selama 24 jam dapat mengakses layanan rawat inap.
Patient safety merupakan komponen vital dan penting dalam asuhan serta langkah untuk memperbaiki mutu layanan yang berkualitas (Findyartini et al, 2015; Cahyono S.B, 2008). Penilaian mutu rumah sakit didapatkan melalui sistem akreditasi, salah satunya adalah sasaran keselamatan pasien karena telah menjadi prioritas untuk layanan kesehatan di seluruh dunia (Join Commission International, 2015; Cosway, Stevens, \& Panesar, 2012). Salah satu langkah memperbaiki mutu pelayanan melalui penerapan budaya keselamatan pasien di rumah sakit baik pemerintah maupun swasta. 
Perawatan rawat inap memiliki peran penting dalam pelayanan perawatan untuk observasi, diagnosis, pengobatan atau upaya perawatan kesehatan lainnya. Keselamatan pasien di rumah sakit melibatkan partisipasi dari semua petugas kesehatan, terutama perawat. Perawat sebagai salah satu tenaga kesehatan yang mempunyai jumlah cukup dominan di rumah sakit yaitu sebesar 50 sampai $60 \%$ dari jumlah tenaga kesehatan yang ada. Pelayanan asuhan keperawatan yang diberikan kepada pasien merupakan pelayanan yang terintegrasi dari pelayanan kesehatan yang lainnya dan memiliki peran yang cukup penting bagi terwujudnya kesehatan dan keselamatan pasien.

Keselamatan pasien adalah sebuah transformasi budaya, dimana budaya yang diharapkan adalah budaya keselamatan, budaya tidak menyalahkan, budaya lapor dan budaya belajar. Dalam proses ini diperlukanupayatransformasionalyangmen yangkut intervensi multi tingkat dan multi tingkat dan multi dimensional yang terfokuspadamisidanstrategiorganisasi,lead ership style,sertabudayaorganisasi.

Pengukuran budaya keselamatan pasien dapat dilakukan berdasarkan dimensi yang mendasari $\mathrm{m}$ ataupunberdasarkantingkatmaturitasdarior ganisasi dalam menerapkan budaya keselamatan pasien. Dikarenakan belum adanya konsensus mengenai standard pengukuran budaya keselamatan pasien, menyebabkanbervariasinyadefinisi,konsep maupun dimensi budaya keselamatan pasien.

\section{METODE}

Metode dalam penulisan ini dilakukan dengan mengumpulkan data dari buku, jurnal, dan thesis dan e-book, kemudian melakukan analisis secara mendalam terkait topik yang dibahas, serta bersifat subjektif yaitu proses penulisan yang lebih fokus pada landasan teori. Dan melakukan analisis buku dan e-jurnal yang relevan dan berfokus kepada pengaplikasian berfikir kritis dalam mengelola informasi dan komunikasi keperawatan. Adapun ejurnal yang digunakan ini adalah dengan menggunakan google dengan memasukkan kata kunci "Keselamatan kerja ”. Jurnal yang digunakan adalah jurnal yang diterbitkan 8 tahun terakhir. Adapun referensi akan dicantumkan dalam penulisan ini dengan jelas terdapat pada daftar pustaka pada bagian akhir penulisan.

\section{HASIL}

\section{1klim Organisasi}

Pengukuran budaya keselamatan pasien dipengaruhi oleh sikap aman dan tidak aman pegawai di level individu, unit kerja dan organisasi. Secara khi.rsus di level 
manajemen senior dalam hal kepemimpinan transformasional yang berbagai penelitian tentang budaya menunjukkan bahwa kepemimpinan transformasional sangat berpengaruh dalam membangun suatu budaya: Untuk mengukur kondisi iklim keselamatan pasien $\mathrm{Ci}$ rumah sakit mencakup 4 hal yang terkait, yaitu kepemimpinan transforrrrasional (di tingkat $\mathrm{CEO}$ /direksiRS), kerjasama tim (di tingkat unit kerja), kesadaran individual (di tingkat individu) serta iklim keselamatan pasien (ditingkat organisasi/ RS).

2. Tingkat Pengetahuan

Tingkat pengetahuan tenaga medis khususnya perawat sangatlah penting dalam meiaksanakan asuhan kepera-watan. Semakin tinggi pengetahuan perawat tentang kode etik dan hukum kesehatan maka semakin baik pula kinerja perawat dalam melaksanakan asuhan keperawatan. Untuk meningkatkan pengetahuan perawat mengenal hukum kesehatan maka perawat harus membaca buku mengenai

kode etik keperawatan dan hukum kesehatan. Selain itu dapat juga melalui teknologi internet serta melalui teman seprofesinYa.

3. PeneraPan Keselamatan Fasien

Perawatan tidak aman Yang dilakukan oleh Petugas kesehatan dirumah sakit menjadi prioritas masalah yang harus segera diselesaikan' $83 \%$ kejadian Yang menYebabkan Pasien tidak aman merupakan kejadian yang seharusnYa bisa dicegah dan 30o/o diantaranya berkaitan dengan kematian pasien.e Adanya tindakan yang tidak aman dikarenakan beberaPa faktor diantaranya tidak kurangnya pelatihan' pengawasan, kegagalan menindaklanjuti kebijakan.e PeneraPan budaYa keselamatan pasien dalam sebuah organisasi tidak terlepas dari Peran aktif atasan (supervisor atau manajer dalam mem- promosikan dan melakukan tindakan-tindakan yang mendukung berjalannya proses penanaman nilai yang dianut' Masih banYak Perawat Yang meng- anggap tindakan supervisor / manajer dalam memPromosikan keselamatan pasien masih rendah, karena masih adanYa Perawat Yang mengganggaP bahwa Peran aktif manajer dalam menanamkan niiai-nilai keselamatan pasien bisa dibilang kurang maksimal'1

\section{Aspek Komunikasi}

Komunikasi yang baik antar petugas medis dengan pasien akan memberikan dampak yang positif terhadap mutu pelayanan kesehatan di suatu rumah sakit serta dimungkinkan menurunkan

kesalahpahaman apabila terjadi kecelakaan, kelalaian dan ataupun mal- praktik. Pelayanan kesehatan yang bermutu yaitu pelayanan kesehatan yang dapat 
memuaskan setiap pemakai jasa pelayanan sesuai dengan kode etik dan standar pelayanan yang telah ditetapkan. Pelayanan perawatan yang sesuai dengan standar memiliki dampak yang lebih besar terhadap citra pelayanan rumah sakit.

\section{Aspek Etika}

Sampai saat ini tenaga kepe-

rawatan belum memiliki landasan hukum yang jelas dan pasti dalam memberikan pelayanan keseharian. Menurut Peraturan Pemerintah l'Jo 32 Tahun 1996 tentang Tenaga Kesehatan, hubungan perawat dan klien merupakan subje hukum. Pemahan perawat mengenai hukum kesehatan memberikan keya- kinan kepada perawat dan menjaga klien untuk selalu berada pada jalut yang aman dengan mengikuti standing order yang telah ditetapkan oleh profesi keperawatan dari pihak rumah sakit yang bersangkutan.

\section{PEMBAHASAN}

Keselamatanpasienrumahsakitadala h:suatusistem dimana rumah sakit membuat asuhan yang lebih aman melalui upaya-upaya, mengidentifikasi resiko, pengelolaan resiko, belajar dari resiko yang terjadi agar tidak terulang dimasa yang akan datang.Dengan lebih sederhana dapat dikatakan keselamatan pasien rumah sakit adalah mencegah kejadian yang tidak diinginkan, apabila tidak dapat dicegah diupayakan agar tidak terulang, melalui upaya belajar dari kesalahan.Keselamatan merupakan prinsip dasar dalam pelayanan pasien dan komponen kritis dari manajemen mutu. (WHO, 2004 dalam Lumenta, 2011).

WHO pada tanggal 2 Mei 2007 menerbitkan panduan " Nine life-saving patient safety solution"

Sembilan solusi keselamatan pasien rumah sakit (KKP-RS, 2008) yaitu:perhatikan nama obat, rupa dan ucapan mirip (Look Alike, Sound- Alike Medication Name), pastikan identifikasi pasien, komunikasi secara benar saat serah terima atau pengoperanpasien,pastikantindakanyangbe narpada sisi tubuh yang benar, kendalikan cairan elektrolit pekat, pastikan akurasi pemberian obat pada pengalihanpelayanan,hindarisalahkateterda nsalah sambung selang gunakan alat injeksi sekali pakai, tingkatkan kebersihan tangan untuk pencegahan infeksinosokomial. KKP-RS dalam Panduan Nasional keselamatan Pasien Rumah sakit membuat sitematika langkah penerapan Keselamatan Pasien Rumah Sakit (KPRS)yangterdiridari3 faseyaitu:fasepersiapan, fasepelaksanaan danfaseevaluasi.

1. FasePersiapan:

Menetapkan kebijakan, rencana jangka pendek

danprogramtahunankeselamatanpasienrum ah sakit. 
2. FasePelaksanaan

Deklarasigerakan

Keselamatan

pasien,program 7langkah keselamatan pasien,penerapan standar akreditasi keselamatan pasien, buat unit sebagai model (pilot project), buat programprogram

kususterkaitkeselamatanpasienseperti,prog ram cuci tangan, dokter penanggung jawab pasien, pelaporandansebagainya,bentukforumdisk usi periodikuntukpengembanganKPRS.

\section{FaseEvaluasi}

Evaluasi menyeluruh setahun sekali untuk memperbaikiprogram KPRS. Mengacu pada hal tersebut, maka RS harus merancang proses baru atau memperbaiki proses yang ada, memonitor dan mengevaluasi kinerja melalui pengumpulan data, menganalisis secara intensif KTD dan melakukan perubahan untuk meningkatkan kinerja serta keselamatan pasien.

Prosesperancangantersebutharusmengacup adavisi, misi dan tujuan RS, kebutuhan pasien, petugas pelayanan kesehatan, kaidah klinis terkini, praktik bisnis yang sehat dan faktor-faktor lain yang berpotensi risiko bagi pasien sesuai dengan "Tujuh Langkah Keselamatan Pasien Rumah Sakit”, yaitu: (DepkesRI, 2008).
1.Bangunkesadaranakannilaikeselamatanp asien. Ciptakan kepemimpinan dan budaya yang terbuka dan adil.

2. Pimpin dan dukung staf anda. Bangunlah komitmen dan fokus kuat dan jelas tentang keselamatan pasien dirumah sakit anda.

3. Integrasikan aktivitas pengelolaan risiko. Kembangkan sistem dan proses pengelolaan risiko ,serta lakukan identifikasi dan assessmen hal yang potensial.

4. Kembangkan sistem pelaporan. Pastikan staf anda agar dengan mudah dapat melaporkan kejadian atau insiden serta RS mengatur pelaporan kepada Komite Keselamatan Pasien Rumah Sakit (KKPRS)

5. Libatkan dan berkomunikasi dengan pasien. Kembangkan cara-cara komunikasi yang terbuka

Dengan pasien

6. Belajar dan berbagi sebuah pengalaman tentang keselamatan pasien. Dorong staf anda untuk melakukan analisis akar masalah untuk belajar bagaimana dan mengapa kejadian itu timbul

7. Mencegah cedera melalui implementasi sistem keselamatan pasien.Gunakan informasi yang ada

tentang kejadian atau masalah untuk melakukan perubahan pada sistem pelayanan. 
Budaya keselamatan pasien yang ada dirumah sakit memiliki hubungan langsung terhadap pelaksanaan pelayanan yang bertujuan untuk menjamin keselamatan pasien. Kemudian budaya keselamatan pasien itu sendiri juga dipengaruhi oleh kepemimpinan transformasional dalam organisasi tersebut.

Ditinjau dari aspek-aspek pem- bentuk budaya keselamatan pasien pada dasarnya hampir seluruh aspek terbilang telah diterapkan dengan baik. Hanya saja berbeda untuk penyerahan dan pemindahan pasien, staf yang adekuat, harapan dan tindakan supervisor/manajer dalam mepromosikan keselamatan pasien, serta respon tidak menyalahkan. Ke empat dimensi tersebut masih terbilang rendah penerapannya karena persentase untuk kategori rendah, yaitu dalam rentang 40$49 \%$.

Hal- hal yang mendukung budaya keselamatan pasien dirumah sakit :

\section{Kerjasama}

Kerjasama merupakan indikator pertama dari budaya keselamatan pasien.

Berdasarkan hasil dari penelitian, dalam melaksanakan asuhan keperawatan kepada pasien perawat akan selalu membutuhkan bantuan dari perawat maupun tenaga kesehatan yang lainnya. Bentuk kerjasama tidak hanya berupa saling membantu pekerjaan ketika perawat dihadapkan pada tugas yang sangat banyak dan membutuhkan penyelesaian yang sesegera mungkin, namun juga bisa berupa pembagian tugas berdasarkan kelompok kecil atau tim dalam satu unit ruang rawat inap. Perawat adalah petugas kesehatan dengan waktu kerja tertinggi yang memberikan 24 jam pelayanan terus menerus, melakukan kolaborasi dengan tim kesehatan lain dan oleh karena hal tersebut dapat menyebabkan risiko terjadinya cidera1

\section{Komunikasi}

Komunikasi sangatlah penting dalam setiap melaksanakan tugas dalam hal ini adalah melaksanakan asuhan keperawatan pada pasien. Komunikasi yang baik dan benar perlu dilakukan untuk mengkoordinasikan asuhan keperawatan yang melibatkan banyak profesi selain profesi perawat.

\section{Kepemimpinan}

Pemimpin harus memiliki komitmen yang kuat terhadap keselamatan pasien, sehingga keselamatan pasien menjadi hal yang utama dalam memberikan pelayanan keperawatan. Pemimpin harus mampu menjadi agen perubahan bagi anak buahnya dengan melaksanakan program keselamatan pasien.

\section{Pelaporan}

Indikator pelaporan dalam penerapan budaya keselamatan pasien berada dalam kategori cukup. Perawat 
diharuskan melaporkan kejadian kesalahan yang tidak disengaja dan kondisi yang mengakibatkan atau berpotensi mengakibatkan cedera yang dapat dicegah pada pasien, yang terdiri dari kejadian tidak diharapkan, kejadian nyaris cedera, kejadian tidak cedera dan kejadian potensial cedera.

5. Respon Tidak Menghukum

Terhadap Kesalahan Indikator respon tidak menghukum terhadap kesalahan ini menunjukkan bahwa dimasa yang akan datang pelaporan terhadap insiden keselamatan pasien tidak semata-mata hanya berupa pelaporan insiden keselamatan, namun pelaporan tersebut hendaknya ditindaklanjuti guna memperbaiki kesalahan dan mencari akar permasalahan, tidak untuk menghukum perawat yang melakukan kesalahan atau berpengaruh terhadap penilainan kinerjanya

\section{PENUTUP}

Keselamatan pasien adalah sebuah transformasi budaya, dimana budaya yang diharapkan adalah budaya keselamatan, budaya tidak menyalahkan, budaya lapor dan budaya belajar. Dalam proses ini diperlukanupayatransformasionalyangmen yangkut intervensi multi tingkat dan multi tingkat dan multi dimensional yang terfokuspadamisidanstrategiorganisasi,lead ership style,sertabudayaorganisasi.
Pengukuran budaya keselamatan pasien dapat dilakukan berdasarkan dimensi yang mendasari $\mathrm{m}$ ataupunberdasarkantingkatmaturitasdarior ganisasi dalam menerapkan budaya keselamatan pasien. Dikarenakan belum adanya konsensus mengenai standard pengukuran budaya keselamatan pasien, menyebabkanbervariasinyadefinisi,konsep maupun dimensi budaya keselamatan pasien.

\section{DAFTAR PUSTAKA}

Buhari, Basok. (2019). BUDAYA

KESELAMATAN PASIEN RUMAH SAKIT PEMERINTAH DAN RUMAH SAKIT SWASTA DI KOTA JAMBI. Jurnal 'Aisyiyah Medika. Volume 3, Nomor 1, Februari 2019.

Herawati, Yennnike Tri. (2015).

$$
\begin{array}{ll}
\text { BUDAYA } & \multicolumn{2}{c}{\text { KESELAMATAN }} \\
\text { PASIENDI } & \text { RUANG RAWAT }
\end{array}
$$

INAP RUMAH SAKIT $X$
KABUPATEN JEMBER. Jurnal IKESMA Volume 11 Nomor 1 Maret 2015

Iriviranty,Afrisya. (2014). Analisis Budaya Organisasi dan Budaya Keselamatan Pasien Sebagai Langkah Pengembangan Keselamatan Pasien di RSIA Budi Kemuliaan Tahun 2014. Jurnal 
Administrasi Rumah Sakit Volume 4 Nomor 3.

Mandriani,Essy. (2018). Analisis Dimensi

Budaya Keselamatan Pasien Oleh

Petugas Kesehatan di RSUD dr

Rasidin Padang Tahun 2018. Jurnal

Kesehatan Andalas. 2019; 8(1)

Pujilestari, Agustina. (2014). BUDAYA

KESELAMATAN PASIEN DI

INSTALASI RAWAT INAP

RSUP DR. WAHIDIN

SUDIROHUSODO KOTA

MAKASSAR. JURNAL MKMI,

Maret 2014, hal 57-64

Putri, S., Santoso, S., \&Rahayu, E. P.

(2018).Pelaksanaan Keselamatan

Pasien dan Kesehatan Kerja

terhadap Kejadian Kecelakaan

Kerja Perawat Rumah Sakit.

JurnalEndurance:KajianIlmiahProb

lemaKesehatan, 3(2), 271-27

Qomariah, S. N., \& Lidiyah, U. A. (2015).

Hubungan Faktor Komunikasi

Dengan Insiden Keselamatan

Pasien (Correlation of

Communication Factor with Patient

Safety Incident). Journals of Ners

Community, 6(2), 166-170.

Rivai, F., Sidin, A., I., \& Kartika, I.

(2016). Faktor Yang Berhubungan

Dengan Implementasi Keselamatan

Pasien Di Rsud Ajjappanng

Soppeng Tahun 2015. Jurnal
Kebijakan Kesehatan Indonesia. 5(4), 152-154.

Sakinah, S., dkk. (2017). Analisis Sasaran

Keselamatan Pasien Dilihat dari

Aspek Pelaksanaan Identifikasi

Pasien dan Keamanan Obat di RS

Kepresidenan RSPAD

GatotSubroto Jakarta. Jurnal

Kesehatan Masyarakat (e-journal),

Vol 5, No4. Hal.145

Simamora, R. H. (2018). Buku ajar

keselamatan pasien melalui

timbang terima pasien berbasis

komunikasi efektif: SBAR. Medan:

USUpress.

Simamora, R. H. (2020). Learning of

Patient Identification in Patient

Safety Programs Through Clinical

Preceptor Models. Medico Legal

Update, 20(3), 553-556.Budaya

dalam lingkup kerja perawat dalam

peningkatan keselamatan pasien

Yasmi,Yulia. (2015). Faktor-Faktor yang

Berhubungan dengan Budaya

Keselamatan Pasien di Rumah

Sakit Karya Bhakti Pratiwi Bogor

Tahun 2015. Jurnal Administrasi

Rumah Sakit Volume 4 Nomor 2. 
